\title{
TOPÔNIMOS LATINIZADOS NA FLORA BRASILIENSIS: o relato de 1818 da Missão Austro-Alemã
}

Leonardo Ferreira Kaltner

(UFF)

\section{RESUMO}

Consiste o presente artigo em estudo na área da Historiografia da Linguística no Brasil, cujo corpus de trabalho é o relato de topônimos brasileiros em Latim científico na obra Flora Brasiliensis, que registram o caminho percorrido pela Missão Austro-Alemã no ano de 1818 no Brasil, pelos naturalistas Carl F. P. von Martius e Johann S. B. von Spix. Além do estabelecimento de texto e da tradução do relato em Latim científico, escrito por Ignaz Urban e publicado em 1906, o texto apresenta a contextualização das obras científicas dos naturalistas, o uso do Latim científico no século XIX e o contexto dos estudos toponímicos na Historiografia da Linguística atual. O trajeto percorrido no Brasil por Spix e Martius em 1818, registrado na obra, entre os atuais estados de São Paulo, Minas Gerais, Goiás e Bahia, faz parte dos antigos caminhos da Estrada Real.

PALAVRAS-CHAVE: Historiografia da Linguística. Latim científico. Carl F. P. von Martius. 


\section{A Missão Austro-Alemã (1817-1820) e a Flora Brasiliensis}

No ano de 2017, serão celebrados os duzentos anos da Missão Austro-Alemã, que percorreu o território do Brasil, tendo esta missão inicialmente acompanhado o séquito real de D. Leopoldina de Habsburgo-Lorena, Arquiduquesa de Áustria, que viria ao Brasil se casar com D. Pedro d'Alcântara, príncipe de Portugal, Algarve e Brasil, futuro imperador. Dos naturalistas austríacos e alemães que compuseram a missão, destacam-se as obras dos acadêmicos da Baviera, Dr. Carl F. P. von Martius (1794-1868) e Dr. Johann B. von Spix (1781-1826), cuja expedição, financiada por Maximiliano José I, rei da Baviera, atravessara o território brasileiro entre os anos de 1817 e 1820 (BARRETO, 2003, p.143-145). A missão científica e artística, composta por acadêmicos naturalistas de formação iluminista, oriundos da Áustria e da Alemanha, teve ativa participação no contexto da Independência no Brasil e do surgimento posterior do Império, após a transferência da Corte em 1808 (FAUSTO, 2006, p. 69).

No âmbito dessa comemoração, há a necessidade de uma reavaliação atual, através de análise linguística e histórica, das publicações e documentos sobre o Brasil resultantes da Missão Austro-Alemã. Essas obras, que compõem também um dos capítulos da Historiografia da Linguística no Brasil, ao confrontar-se o pensamento linguístico da época com a descrição das línguas indígenas, registram fenômenos linguísticos que podem auxiliar a traçar a história linguística no Brasil oitocentista. Entre as mais singulares dessas obras estão, por exemplo, os Glossaria Linguarum Brasiliensium (Glossários das Línguas Brasileiras) de 1863, de Carl F. P. von Martius. O naturalista bávaro legou registros à posteridade em diversos campos do saber no alvorecer do cientificismo europeu, sobre o Brasil:

Os seus monumentais trabalhos no campo da botânica se transformaram rapidamente em obras de referência e, ainda hoje, são consultadas com proveito por cientistas de todo o mundo. O estudo que dedicou às palmeiras, a Historia naturalis palmarum (1823-1850), que inclui espécies dos quatro cantos do planeta, mereceu um exultante comentário de Alexander von Humboldt (1769-1859), o decano dos viajantes europeus no continente americano (apud Eichler 1869:13). E o poeta Johann Wolfgang von Goethe (1749-1832) escreveu uma resenha imediatamente depois de aparecer os dois primeiros fascículos dessa obra, qualificando-a de a mais bela publicação botânica de todos os tempos 
(Goethe 1989 (12):384). A Flora brasiliensis, por sua vez, o maior projeto editorial empreendido por Martius, é uma obra de fôlego que teve início em 1840 e foi concluída, postumamente, em 1906, vale dizer, 38 anos depois da sua morte (DIENER, 2014, p. 354).

Este artigo é resultado de pesquisa no campo da Historiografia da Linguística no Brasil, pela análise de relatos referentes à Missão Austro-Alemã. Assim, traduzimos e analisamos linguisticamente a descrição dos topônimos da viagem dos naturalistas bávaros ao Brasil, descritos na rota da expedição em 1818. O relato que apresentamos foi publicado em Latim Científico no primeiro volume da obra Flora Brasiliensis, tendo sido Ignatz Urban responsável por sua autoria (URBAN, 1906, p. 58-59). Nossa análise está desenvolvida no estabelecimento de texto do original latino, sua tradução e uma análise geral dos topônimos brasileiros, registrados em Latim, para descrever a passagem dos naturalistas pelo Brasil no ano de 1818, em que os naturalistas bávaros saem de São Paulo, em direção a Minas Gerais, passando por Goiás, por fim chegando à Bahia:

Spix and Martius collected in Brazil between 1817 and 1820. Detailed information about their itineraries and the places visited can be found in Spix and Martius (1823, 1828, 1831a, 1831b, 1968), Urban (1906), Papavero (1971), and in Tiefenbacher (1983). The journey itself began on the 8th of December 1817, with São Paulo as the first destination, reaching it by the end of the year (31st of December). In 1818, they left São Paulo for southern Bahia, gathering large collections especially in Minas Gerais and Bahia, where they arrived in November 1818 (MORAES \& FACADE, 2015, p.167).

O uso do Latim Científico como meio de expressão no século XIX é fenômeno de estudos e de observação da Historiografia da Linguística, sobretudo em relação às obras de naturalistas, que descreveram a natureza no Brasil, em perspectiva internacional, através do discurso científico da época. O uso do latim era propositado, sobretudo para proporcionar uma visão internacionalizante e cooperativa das ciências naturais no continente europeu:

(...) utilizar o latim e as vozes gregas latinizadas (raramente em estado puro); isto se tornou praticamente exequível desde 1753, quando o genial Carlos de Lineu introduziu a nomenclatura binária por meio de sua famosíssima obra Species Plantarum. Em 1867 o Congresso Internacional de Botânica - reunido em Paris - ratificou o emprego do latim (RIZZINI, 1955, p.11-12). 
A obra Flora Brasiliensis (Flora Brasileira), em que o relato foi publicado, é um monumento da História da Ciência, sua edição foi financiada, inicialmente pelo imperador da Áustria Ferdinando I, também por Ludovido I, rei da Baviera, e, por fim, pelo imperador D. Pedro II, tendo sido publicada ao longo de décadas, entre 1840 e 1906 (ROYAL SOCIETY, 1869-1870, p.7). O trabalho enciclopédico de Botânica consta de 15 volumes, divididos em 40 partes e diversos fascículos, com textos em Latim Científico e imagens, sendo um dos mais completos trabalhos de Botânica já realizados:

A Flora brasiliensis foi produzida entre 1840 e 1906 pelos editores Carl Friedrich Philipp von Martius, August Wilhelm Eichler e Ignatz Urban, com a participação de 65 especialistas de vários países. Contém tratamentos taxonômicos de 22.767 espécies, a maioria de angiospermas brasileiras, reunidos em 15 volumes, divididos em 40 partes, com um total de 10.367 páginas (CRIA, 2016).

Inicialmente, seu organizador foi o naturalista Carl F. P. von Martius, tendo este sido sucedido por August Wilhelm Eichler e, em seguida, por Ignatz Urban. No primeiro volume da Flora Brasiliensis, foram editadas, posteriormente, as Vitae Itineraque Collectorum Botanicorum (Vidas e itinerários dos botânicos coletores), em sua última edição, contendo um resumo biográfico, bibliográfico e de itinerário percorrido por diversos botânicos de variadas nacionalidades que colaboraram para a criação da obra. Esse relato, editado no primeiro volume, foi escrito por Ignatz Urban e será o texto estabelecido e analisado mais adiante, com o registro dos topônimos da expedição de Carl F. P. von Martius em 1818.

Faz-se necessária uma nova análise e releitura de textos e discursos de cientistas naturalistas que percorreram o país, no contexto da Historiografia da Linguística no Brasil e dos Estudos Culturais, campos de investigação que podem favorecer a uma interpretação de documentos e textos relativos ao processo de descolonização do Brasil, estando inseridos em contextos e processos de interação e de contato intercultural e linguístico (FARACO, 2016, p. 148-155). Podemos, por meio desses relatos, entrever também a recepção de ideias linguísticas no contexto da Independência no Brasil e a sua relação com a construção social e política de uma identidade cultural que serviria para o processo de padronização e, até mesmo, da gestão da diversidade linguística no Império, com a constituição de uma sociedade multicultural, a partir da Independência do Estado no Brasil: 
Nos oitocentos, a partir da vinda da família real ao Brasil se deu início à instauração de estabelecimentos culturais (por exemplo, imprensa, biblioteca, museu real, jardim botânico), instituições acadêmicas (escolas de Direito em São Paulo e em Recife) e instituições de pesquisa (Instituto Histórico e Geográfico, Instituto Manguinhos). Tem-se, com isso, a formação de um grupo intelectualizado que passou a integrar movimentos sociais. Muitos desses, embalados pelas ideologias do iluminismo, do darwinismo e do positivismo, defendiam as causas abolicionistas, republicanas e nacionalistas, além da separação da igreja do Estado. Tratava-se, para esses intelectuais, de "legitimar ou respaldar cientificamente suas posições nas instituições de saber de que participavam e por meio delas" (Schwarcz, 2008, p. 26). Logicamente, o cientificismo não funcionou alheio às práticas de governo, mas as fundamentou e as legitimou. D. Pedro II pode ser tomado como o símbolo político da fusão entre a ciência e o governo: Como Luís XIV, o imperador afirmava reiteradamente "a sciencia sou eu" (Schwarcz, 2008) (SEVERO, 2013 p.112).

As representações linguísticas e discursivas sobre o Brasil à época da Independência são registros do início do processo de descolonização, que se inicia com a transferência da Corte Portuguesa em 1808, e remetem, direta ou indiretamente, à criação de uma identidade linguística e cultural no Brasil. Esse processo, que culminaria com a Independência em 1822, passa por um questionamento posterior sobre Língua, Estado e nação, com a busca por uma interpretação da formação e da origem do Brasil. Dessa forma, cumpre salientar que a História da Linguística neste recorte histórico no Brasil se encontra com o questionamento cientificista do século XIX:

Esse cientificismo, na forma do naturalismo e do darwinismo, também embalava os registros feitos por um amplo e diversificado grupo de viajantes e exploradores no Brasil do século XIX. Tais viajantes produziram relatos e ilustrações de tudo que observavam, experimentavam e ouviam. Tratava-se da produção de saberes segundo certas regras, cujo funcionamento geral se baseava em lançar "um olhar minucioso sobre as coisas e transcrever, em seguida, o que ele recolhe em palavras lisas, neutralizadas e fiéis" (Foucault, 1990, p. 179), sendo que "todo capítulo concernente a um animal qualquer deve[ria] ter os seguintes passos: nome, teoria, gênero, espécie, atributos" (Idem, p. 178). Esse olhar naturalista que destrincha, disseca, observa e registra possibilitou a produção de uma série de saberes sobre o Brasil por diferentes grupos de exploradores: Entre os naturalistas que registraram detalhadamente espécies botânicas e animais, estavam Saint-Hilaire, 
Carl Phillipp Von-Martius, Edward Pohl e Johann von Spix. Entre os militares, destacavam-se Leithold e Raugo. Dentre os especialistas da Coroa, estava o mineralogista Eschwege. Havia também viajantes das burguesias francesa e inglesa, entre eles John Luccock, Koster e Tollenare (Kury, 2001; Lahuerta, 2006) (SEVERO, 2013 p.112).

Das publicações de Carl F. P. von Martius neste aspecto, além das publicações na área de Botânica, temos reflexões iniciadas na obra Reise in Brasilien (Viagem ao Brasil), obra do gênero de Literatura de Viagens, que descreve a Missão de 1817 a 1820, e faz reflexões sobre as políticas que poderiam ser desenvolvidas ao longo do período imperial posterior, questões estas que foram posteriormente desenvolvidas na monografia endereçada ao Instituto Histórico e Geográfico Brasileiro (IHGB): Como se deve escrever a história do Brasil, publicada na revista do instituto em 1844 (MARTIUS, 1845, p. 381-403), sobre a historiografia no Brasil (GUIMARÃES, 2000, p.389-390), assim como seu único romance literário Frey Apollonyo, ein Roman aus Brasilien (Frei Apolônio, um romance do Brasil) de 1831, que veio a lume à posteridade graças ao empenho do especialista Erwin Theodor Rosenthal, que o traduziu e reeditou em 1992, a partir da comparação de manuscritos (ROSENTHAL, 1992, p. 5 e seguintes).

Para a Historiografia da Linguística nos interessam também as ideias científicas de Carl F. P. von Martius e de seus pares, desde os relatos sobre línguas indígenas, o contato linguístico até políticas linguísticas que se possam perceber nas descrições da sociedade no Brasil. É patente a influência do pensamento filológico e da linguística comparativa no século XIX, como resultado do empirismo e da visão cosmopolita que os naturalistas austríacos e alemães dessa época apresentam, por influência de Wilhelm e Alexander von Humboldt, ainda que elementos anacrônicos, para a ciência atual se desenvolvam em paralelo na ciência oitocentista, como o eurocentrismo hegeliano e o etnocentrismo, por influência darwinista, e estejam registrados em obras e no pensamento acadêmico europeu da época sobre as Américas também (BARBOSA, 2013, p.93). 


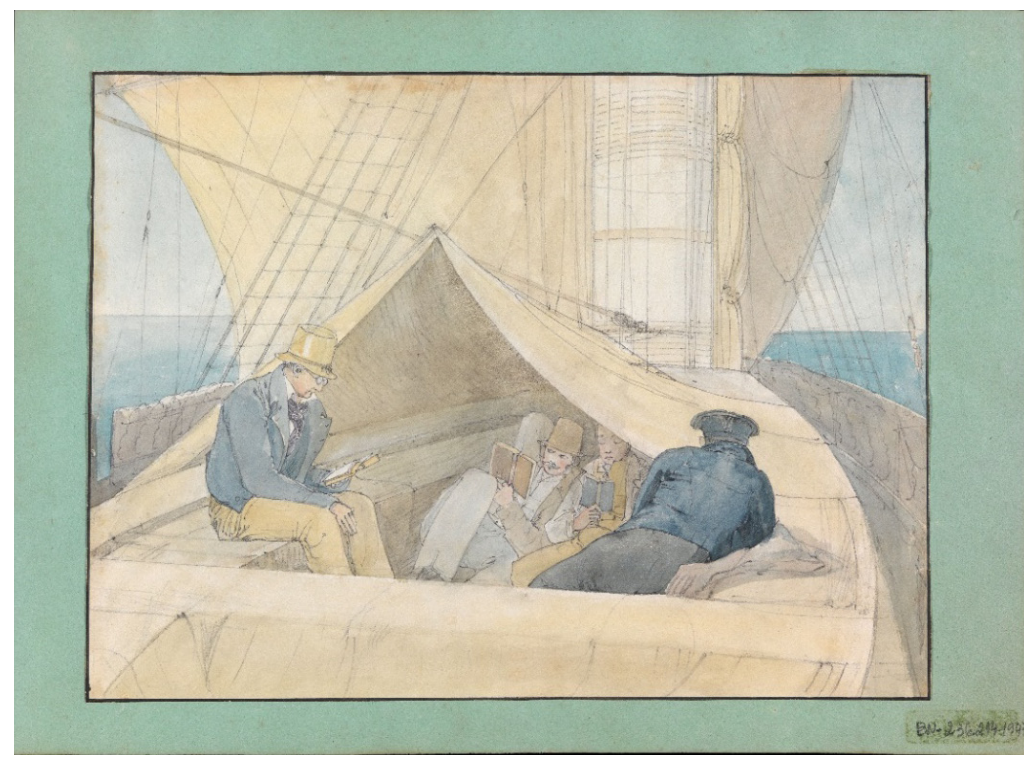

A fragata que trouxe os naturalistas ao Brasil (Th. Ender)

\section{Reise in Brasilien: a viagem ao Brasil, de 1817 a} 1820

Apresentamos excerto da obra Reise in Brasilien (Viagem ao Brasil), obra conjunta de Martius e Spix, que relata os objetivos imediatos da Missão Austro-Alemã de 1817 a 1820, e a seguir, apresentamos tradução deste fragmento. Cumpre salientar que a obra Reise in Brasilien foi publicada em três volumes, originalmente, em 1823, 1828 e 1831, em alemão, tendo por financiamento a Casa Real da Baviera, como consta no frontispício de sua editio princeps. $\mathrm{O}$ fragmento selecionado apresenta $\mathrm{O}$ plano original de pesquisas da Missão Austro-Alemã no Brasil, dentro das concepções científicas do início do século XIX. A tradução integral em Língua portuguesa desta obra foi encomendada pelo Instituto Histórico e Geográfico Brasileiro (IHGB) e realizada por Lúcia Furquim Lahmeyer, publicada, inicialmente, em 1938 pela Imprensa Nacional (SPIX \& MARTIUS, 1981, p. 9-12). 
Reise in Brasilien (SPIX \& MARTIUS, 1823, p. 5-6):

Diesen Aufträgen zufolge wurde die Bereicherung der beiden Fächer, der Zoologie nämlich und der Bolanik, den Reisenden zur Haupt-Pflicht gemacht, zugleich aber mittelbar die Berücksichtigung der übrigen Zweige der Wissenschaft, soweit es Zeit und Umstände zuliessen, anempfohlen. Dr. SPIX, als Zoolog, verpflichtete sich, das gesammte Thierreich zum Gegenstande seiner Beobachtungen und Beschäftigungen zu machen. In dieser Beziehung hatte er Alles, was den Menschen, den Ureinwohner sowohl als den Eingewanderten, seine klimatischen Verschiedenheiten, seinen körperlichen und geistigen Zusland u. s. w. betrifft; den aussern und innern Bau der daselbst lebenden Thiere aller Klassen, von den höchsten bis zu den niedrigsten, ihre Gewohnheiten und Instincte, ihre geographische Verbreitung und Wanderung, so wie endlich die unter-irdischen Reste von Thieren, diese sichersten Documente der Vergangenheit und der allmähligen Entwickelung der Schöpfung, zu beachten.

- Dr. MARTIUS, als Botaniker, übernahm die Bestimmung, die tropische Pflanzenwelt in ihrer ganzen Ausdehnung zu erforschen. Neben dem Studium der dort vorzugsweise einheimischen Familien lag ihm die Untersuchung derjenigen Formen besonders ob, welche durch ihre Verwandtschaft oder Identität mit denen anderer Länder Schlüsse über das ursprüngliche Vaterland und die allmählige Verbreitung derselben auf der Erde gestatten. Diese Forschung wollte er mit der Berücksichtigung der klimatischen und geognostischen Verhältnisse in Verbindung bringen, und deshalb auch auf die niedrigsten Bürger des Pflanzenreiches, wie die Moose, Flechten und Pilze ausdehnen. Die Veränderungen, welche sowohl die einheimisehen, als die eingeführten Pflanzen unter gewissen äusseren Einflüssen erleiden, die Geschichte des Bodens und der dort gebräuchlichen Cultur sollten eben so sehr seine Aufmerksamkeit in Anspruch nehmen. Von der Untersuchung des inneren Baues und der Entwicklung der tropischen Gewächse liessen sich interessante Aufschlüsse über die Gesetze des Pflanzenlebens überhaupt, so wie von der Beobachtung etwa vorkommender Spuren einer früheren, nun untergegangenen, Vegetation Materialien für die Begründung geognostischer Ansichten erwarten. Endlich glaubte er durch eine genaue Erforschung der brasilianischen Arzney-körper aus dem Pflanzenreiche, so wie aller übrigen vegetabilischen Stoffe, deren Benützung für Künste und Gewerbe dienlich werden könnte, und durch sorgfältige Aufzeichnung der Art und Weise, wie solche in ihrem Vaterlande angewendet werden, dem Zwecke seiner Sendung $z u$ entsprechen. Hauptsächlich aber machte man es uns, nebst den 
Beobachtungen und wissenschaftlichen Forschungen im Gebiete unserer speciellen Fächer, bey welchen wechselseitige Hülfe und Unterstützung vorausgesetzt wurde, zur Obliegenheit, die akademischen Sammlungen durch Uebersendung aller Naturproducte aus sammtlichen Reichen, als der besten Belege für die gemachten Beobachtungen, möglichst zu vervollständigen.

\section{Tradução}

Conforme esta ordem, foi recomendada a fortuna crítica de duas disciplinas, a saber a Zoologia e a Botânica, tornando-se para os viajantes a principal exigência. Simultaneamente, porém, de forma indireta, foi recomendada a consideração dos restantes ramos da ciência, enquanto o permitissem tempo e circunstâncias. Dr. Spix, como zoólogo, se comprometeu com todo o mundo animal, como objeto de estudo de suas observações e tarefas a realizar. Nesta relação, ele se ocupou de observar tudo o que é relativo aos homens, aos indígenas assim como aos imigrantes, sua diversidade quanto ao clima, sua condição corporal e espiritual entre outras; ocupou-se de observar tudo o que é relativo à estrutura anatômica externa e interna dos animais lá viventes, de todas as classes, dos maiores até os menores, seus hábitos e instintos, sua distribuição geográfica e imigração, assim como, por fim, os resíduos fósseis dos animais, estes os mais seguros documentos do passado e da evolução gradual da Criação.

Dr. Martius, como botânico, aceitou a determinação de pesquisar o mundo das plantas tropicais em sua extensão total. Ao lado do estudo das famílias das plantas, de preferência as nativas de lá, cabia a ele a observação dessas formas nativas, particularmente, caso permitissem algumas conclusões, através de seu parentesco ou comparação com aquelas de outros países, além da pátria original, e sua sucessiva propagação própria sobre a Terra. Desejava ele produzir esta pesquisa com a consideração das relações climáticas e geognósticas em associação e, por isso, desejava ele ampliá-las também aos menores reinos das plantas, como os musgos, líquens e fungos. As transformações que padecem não só as plantas nativas, mas também as introduzidas, sob conhecidas influências externas, a história dos solos e a cultura lá usual deviam igualmente exigir muito de sua atenção. A partir da investigação da estrutura interna e do desenvolvimento das plantas tropicais, podia-se prever interessantes esclarecimentos da vida das plantas em geral, assim como a partir da observação de alguns vestígios fósseis, que sucedem de antiga vegetação, agora so- 
terrada, como material para a justificativa da projeção geognóstica. Por fim, acreditava ele que, através de uma precisa investigação dos produtos medicinais brasileiros, pelos reinos das plantas, assim como de todo o restante da matéria vegetal, cujo uso para as artes e a indústria pudessem se tornar oportunas, e, através de cuidadosa descrição da espécie e do aspecto, como semelhantes plantas são aplicadas em sua terra natal, corresponderia à intenção de sua missão. Fazia-se principalmente necessário para nós, porém, junto às observações e às pesquisas científicas no campo de nossas disciplinas específicas, pelas quais uma ajuda mútua e apoio eram presumidos, como obrigação, completar o mais rápido o possível a coleção acadêmica, pelo envio de todos os produtos naturais, oriundos de todos os reinos, como as melhores provas para as observações realizadas.

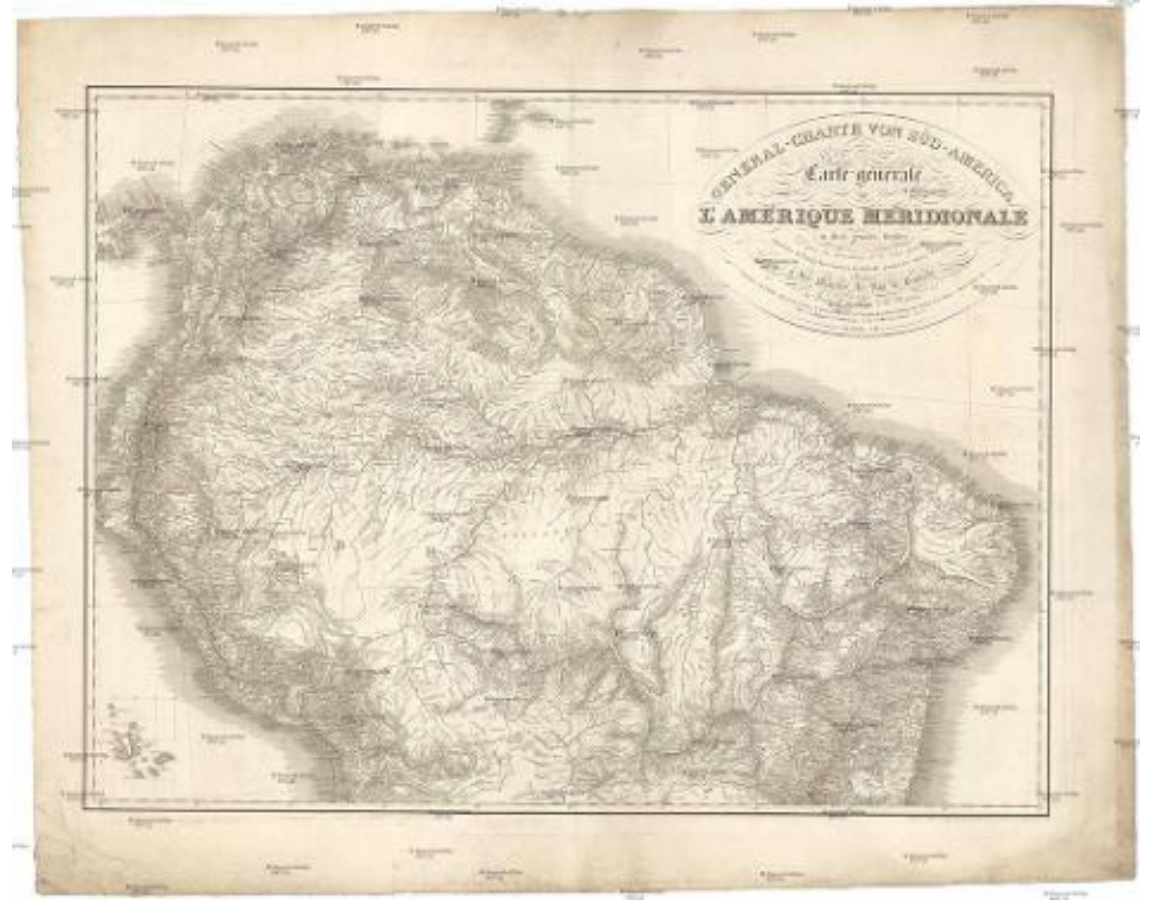

General Charte von Südamerika de Martius e Spix (2016) 


\section{O itinerário de 1818: topônimos em Latim Científico}

O texto a seguir, estabelecido a partir da obra Flora Brasiliensis, apresenta o registro dos topônimos, com as datas precisas, visitados pela Missão Austro-Alemã no ano de 1818, tema central do artigo. Este trecho compõe o chamado Caminho Velho na antiga Estrada Real. Carl F. P. von Martius e Johann B. P. von Spix percorreram um itinerário que vai de São Paulo a Minas Gerais, de lá até Goiás, e, por fim, até a Bahia, com uma tropa de mulas:

1818. S. Paulo (31. XII. 17-9.I. 18), mons Jaragua, Jacarehy, Cutia, S. Roque, Villa de Sorocaba, Ypanema (per 14 dies), iter ad Villa do Porto feliz, Sorocaba, Ytú, Jacaré, Jundiahy, Campo largo, Morro de Catetuva, J. Joao de Atibaya, Boa-vista, Morro de Lopo, civit. Minas Geraes: Morro grande, Arr. de Camanducaya, Rosetta, Campiuh, Estiva, Rio Mandú, Rio Servo, S. Vincente, S. Anna de Sapucahy, S. Barbara, Rio Sapucahy, Serra de S. Gonzalo, Serra de Paciencia, S. Gonzalo, Villa de Campanha (Villa da Princesa da Beira, 13. II.), Arr. do Rio Verde, Rio do Peixe, Campo Bello, Faz. do Corrego dos Pinheiros, Capella de S. Antonio, Faz. de Parapitinga, Serra Branca, Rio Ingahy, Serra Capivary, Rio Grande, Ponte nova, Serra de Viruna, Faz. da Vittoria, Rio das Mortes, Morro de Bom-fim, Morro Lenheiro, Villa de S. Joao d'El Rey, Serra de S. José, S. José, Faz. Canduahy, Lagoa doirada, Capella de S. Eustachio, Faz. de Camaboao, Rio Paraopeba, Serra de Congonhas, Rio Congonhas, Morro da Solidade, Chapada (Ita-beba), Faz. da Chapada, Faz. José Correa, Rodeio, Serra de Oiro Branco, Morro de Gravier, Faz. Capao, Faz. Lana, Trepui, pedes Itacolumi, Villa Rica (Ouro Preto, usque 31. III.), Tacoaral, Passagem, Rib. do Carmo, Mariana, Ourives, Rio Mainarde, Faz. dos Cristaës, Oiro fino, Rib. do Bacalhao, S. Anna dos Ferros (Barra do Bacalbao), Rio Piranga, Rio Turvo, Venda das duas Irmaos, Capella de S. Rita, Serra de S. Geraldo, Presidio de S. Joao Baptista (usque 10. IV.), Aldea do Morro Grande, Faz. Guidowald, Serra da Onca, Rio Xipotó, retro ultra S. Joao Baptista, Arr. de S. Jose Barboza, Sitio, S. Rita, Oiro fino, Mariana ad Ouro Preto (21. IV.), adscensus montis Itacolumi, Capao, Faz. Laranjal, Faz. Pires, Prata, Chapada, Serra de Deos te livre (da Solidade), Morro de Gravier, Ouro Preto, Morro de Villa Rica, Corrego d'Andrada, Rio das Velhas, Antonio Pereira, Arr. do Bento Rodrigues, Inficionado, Serra de Caraça, Hospicio da Mai dos Homens, Inficionado, Cata Preta, Arr. do Bento Rodrigues, Ouro Preto (28. IV. ad initium V). Dein Serra da Caxoeira, Bandeirinha, Arr. de S. Antonio da Casa branca, Rio das Pedras, Faz. Coxe d'agoa, S. Antonio de cima, S. Rita, Sabará, Morro de Valerio, Caeté 
(Rainha), Serra de Piedade, S. Joao do Morro grande, Cocaës, Faz. Cabo d'Agosta, Faz. Tangue, Rio das Onças, Serra da Itambé, Arr. do Rio do Peixe, Morro do Gaspar Soares, Corrego das Lages, Soumidoro, Arr. da S. Conceição, Rio de S. Antonio, Serra Coati, Onça, Bom successo, Taparoca, Arr. Taponhoacanga, Faz. Donna Roza, Faz. Rio do Peixe, Villa do Principe, Rancho das tres Barras, Arr. Milho Verde, Vao, Faz. Palmital, Rio Jequetinhonha, Tejuco (Diamantina), Lavra das Picas, Bandeirinha, Curralinho, Rib. do inferno, Serviço Matta Matta, Serviço dos Calderoës, adscensus montis Itambé da Villa (5. VI.). Dein a Tejuco ad Serra de Mentanha, Arr. do Rio Manzo, Cangicas, Capao Grosso, Lavras da Pindaiba, Buriti, Faz. Pe do Morro, Rib. de S. Domingos, Columbi, Arr. de Barreiras, Rib. Curralinho, Rio Arassuahy, Rio Itamarandiba, Piedade, Villa Bom Successo (Fanado), Bem Posto, Quartel do Alto dos Boys, 13. VI. ad Arr. da Chapada, Agoa-Suja, Arr. Sucuriuh d'acima, Agoada Nova, Morro de Agoada Nova, Gupiara (Calhao), Corr. de S. Anna, S. Domingos, 4. VII. iter ultra Faz. de S. Joaquim, trans Rio Jequetinho, Porto dos Angicos in Sertao ad Morro Retondo, Munbucas, Bananal, Serra do Grao Mogol, Itacambirussu, Faz. Congonhas do Campo, Faz. Joaquim Pereira, Arr. de Formigas (12.-17. VII.), Serra de Vicente (Cabeceira do Rio dos Boys), Rib. Riachao, Contendas (per tres hebdomades), Campos Geraës de S. Felipe, Faz. Tamandua (12. VIII.), Tapera, Rio S. Francisco, Faz. Capao, Faz. Mangahi, Pedras da Cruz (de baixo), Porto de Salgado, trans Rio S. Francisco ad Brejo de Salgado (usque 1. IX.), Serra de Salgado, mons Itabirasava, Faz. Sumidouro, Rio das Pedras, Serra das Araras, Sete Lagoas, Agoa Doce, Rib. Patos, Rib. dos Boys, Yhá, Rio Caranhanha, Vao do Paranán, Faz. do Rio Fermozo, Rib. Paratinga, Contagem de S. Maria, civit. Goyaz Faz. de S. Roque, Serra do Meio, civit. Minas Geraës Contagem de S. Maria, Faz. do Rio Fermozo, Rib. Juquery, Rio Fermozo, ultra Caranhanha prov. Bahia (olim ad Pernambuco pertin.) Arr. Caranhanha (usque 24. IX.) trans Rio S. Francisco ad Malhada, Faz. Curralinho, Faz. Pe da Serra, Serra dos Montes Altos, Faz. Carnaibas, Paxaú, Serra da Gamelleira, Serra de Cayteté, Hospicio, Caytete (Villa nova do Principe), Faz. Joazeiro, Faz. da Lagoa d'Aguda, Serra de Joazeiro, Faz. Tapera, Villa Velha, Rio Brumado, Serra do Rio de Contas, Villa do Rio de Contas (usque 17. X.), Serra da Villa Velha, Morro Retondo, Rib. Brumadinho, Caza de Telha, Faz. Secca, Serra das Lages, Rib. Peruaguaçuzinho, Sincorâ, Serra de Sincorâ, Faz. Carabatos, Olho d'Agoa, Rib. Jacaré, Arr. de Maracâs, Faz. Rio Secco, Tapera, Villa da Pedra Branca, Curralinho, Genipapo, Salgado, Catingas, Torto, Rio Paraguassú, Porto de S. Feliz, Villa de Cachoeira, Engenho da Ponte (7. XI), Itaparica, Bahia (10. XI-11. XII.), navi ad Ilheos, Rio Fundao, Rio Itahype, Al- 
mada, Lagoa de Aimada, Villa de S. Pedro de Alcantara (As Ferradas) (MARTIUS, 1840, p. 58-59).

\section{Tradução}

No ano de 1818, em São Paulo (de 31.12.1817 a 9.01.1818): monte Jaraguá, Jacareí, Cutia, São Roque, Vila de Sorocaba, Ipanema (por 14 dias), caminho para a Vila do Porto Feliz, Sorocaba, Itu, Jacaré, Jundiaí, Campo Largo, Morro de Catetuva, São João de Atibaia, Boa Vista, Morro do Lopo. Na capitania de Minas Gerais: Morro Grande, Arraial de Camanducaia, Roseta, Campinho, Estiva, Rio Mandu, Rio Servo, São Vicente, Santana do Sapucaí, Santa Bárbara, Rio Sapucaí, Serra de São Gonçalo, Serra de Paciência, São Gonçalo, Vila de Campanha (Vila da Princesa da Beira, 13.02.1818), Arraial do Rio Verde, Rio do Peixe, Campo Belo, Fazenda do Córrego dos Pinheiros, Capela de Santo Antônio, Fazenda de Parapitinga, Serra Branca, Rio Ingaí, Serra Capivari, Rio Grande, Ponte Nova, Serra de Viruna, Fazenda da Vitória, Rio das Mortes, Morro de Bonfim, Morro Lenheiro, Vila de São João del Rei, Serra de São José, São José, Fazenda de Canduaí, Lagoa Dourada, Capela de São Eustáquio, Fazenda de Camaboão, Rio Paraopeba, Serra de Congonhas, Rio Congonhas, Morro da Solidade, Chapada (Ita-beba), Fazenda da Chapada, Fazenda José Correa, Rodeio, Serra de Ouro Branco, Morro de Gravier, Fazenda Capão, Fazenda Lana, Trepuí, o sopé de Itacolumi, Vila Rica (Ouro Preto, até 31.03.1818), Tacoaral, Passagem, Ribeirão do Carmo, Mariana, Ourives, Rio Mainarde, Fazenda dos Cristais, Ouro Fino, Ribeirão do Bacalhau, Santana dos Ferros (Barra do Bacalhau), Rio Piranga, Rio Turvo, Venda das duas Irmãs, Capela de Santa Rita, Serra de São Geraldo, Presídio de São João Batista (até 10.04.1818), Aldeia do Morro Grande, Fazenda Guidowald, Serra da Onça, Rio Xopotó, de volta para além de São João Batista, Arraial de São José Barbosa, Sítio, Santa Rita, Ouro Fino, Mariana até Ouro Preto (21.04.1818), subida do monte Itacolumi, Capão, Fazenda Laranjal, Fazenda Pires, Prata, Chapada, Serra do Deus-te-livre (da Solidade), Morro de Gravier, Ouro Preto, Morro de Vila Rica, Córrego de Andrada, Rio das Velhas, Antônio Pereira, Arraial do Bento Rodrigues, Inficionado, Serra de Caraça, Hospício de Nossa Senhora Mãe dos Homens, Inficionado, Cata Preta, Arraial de Bento Rodrigues, Ouro Preto (de 28.04.1818 até o início de maio). A partir daí, Serra da Cachoeira, Bandeirinha, Arraial de Santo 
Antônio da Casa Branca, Rio das Pedras, Fazenda Cocho d'Água, Santo Antônio de Cima, Santa Rita, Sabará, Morro de Valério, Caeté (Rainha), Serra de Piedade, São João do Morro Grande, Cocais, Fazenda Cabo de Agosto, Fazenda do Tangue, Rio das Onças, Serra de Itambé, Arraial do Rio do Peixe, Morro do Gaspar Soares, Córrego das Lages, Sumidouro, Arraial de Santa Conceição, Rio de Santo Antônio, Serra Coati, Onça, Bonsucesso, Taparoca, Arraial Tapanhoacanga, Fazenda Dona Rosa, Fazenda Rio do Peixe, Vila do Príncipe, Rancho das Três Barras, Arraial Milho Verde, Vão, Fazenda Palmital, Rio Jequetinhonha, Tejuco (Diamantina), Lavra das Picas, Bandeirinha, Curralinho, Ribeirão do Inferno, Serviço Mata-Mata, Serviço dos Calderões, subida do monte Itambé da Vila (05.06.1818). Então, do Tejuco à Serra do Mendanha, Arraial do Rio Manso, Canjicas, Capão Grosso, Lavras da Pindaíba, Buriti, Fazenda Pé do Morro, Ribeirão de São Domingos, Columbi, Arraial de Barreiras, Ribeirão Curralinho, Rio Araçuaí, Rio Itamarandiba, Piedade, Vila Bonsucesso (Fanado), Bem-Posto, Quartel do Alto dos Bois, 13.06.1818 até Arraial da Chapada, Água-Suja, Arraial de Sucuruiú de Acima, Aguada Nova, Morro de Aguada Nova, Gupiara (Calhau), Córrego de Santana, São Domingos, 4.07.1818 caminho além da Fazenda de São Joaquim, através do Rio Jequetinho, Porto dos Angicos no sertão até o Morro Redondo, Mumbucas, Bananal, Serra do Grão-Mogol, Itacambiruçú, Fazenda Congonhas do Campo, Fazenda Joaquim Pereira, Arraial de Formigas (de 12.07.1818 até 17.07.1818), Serra de Vicente (Cabeceira do Rio dos Bois), Ribeirão Riachão, Contendas (por três semanas), Campos Gerais de São Felipe, Fazenda Tamanduá (12.08.1818), Tapera, Rio São Francisco, Fazenda Capão, Fazenda Mangai, Pedras da Cruz (de baixo), Porto de Salgado, através do Rio São Francisco até o Brejo de Salgado (até 01.09.1818), Serra de Salgado, Monte Itabiraçava, Fazenda Sumidouro, Rio das Pedras, Serra das Araras, Sete Lagoas, Água Doce, Ribeirão dos Patos, Ribeirão dos Bois, Iá, Rio Carinhanha, Vão do Paranã, Fazenda do Rio Formoso, Ribeirão Paratinga, Contagem de Santa Maria, na capitania de Goiás: Fazenda de São Roque, Serra do Meio, na capitania de Minas Gerais: Contagem de Santa Maria, Fazenda do Rio Formoso, Ribeirão Jequeri, Rio Formoso, além de Carinhanha na província da Bahia (outrora pertencente a Pernambuco), Arraial Carinhanha (até 24.09.1818), através do Rio São Francisco até Malhada, Fazenda Curralinho, Fazenda Pé da Serra, Serra dos Montes Altos, Fazenda Carnaíbas, Paxaú, Serra da Gameleira, Serra de Caiteté, Hospício, Caiteté (Vila nova do Prínci- 
pe), Fazenda Juazeiro, Fazenda da Lagoa d`Aguda, Serra de Juazeiro, Fazenda Tapera, Vila Velha, Rio Brumado, Serra do Rio de Contas, Vila do Rio de Contas (até 17.10.1818), Serra da Vila Velha, Morro Redondo, Ribeirão Brumadinho, Casa de Telha, Fazenda Seca, Serra das Lages, Ribeirão Peruaguaçuzinho, Sincorá, Serra de Sincorá, Fazenda Carabatos, Olho d`Água, Ribeirão Jacaré, Arraial de Maracás, Fazenda Rio Seco, Tapera, Vila da Pedra Branca, Curralinho, Jenipapo, Salgado, Catingas, Torto, Rio Paraguaçú, Porto de São Félix, Vila de Cachoeira, Engenho da Ponte (7.11.1818), Itaparica, Bahia (10.11.1818 - 11.12.1818), de navio a Ilhéus, Rio Fundão, Rio Itaípe, Almada, Lagoa de Aimada, Vila de São Pedro de Alcântara (As Ferradas).

\section{Considerações finais}

A toponímia é parte da onomástica, ramo da lexicografia que estuda os nomes próprios relativos a lugares, acidentes geográficos, paisagens e regiões naturais, sendo estas habitadas ou não, cuja denominação serve à divisão institucional de territórios, sendo estabelecidas e atribuídas por comunidades linguísticas. Desta forma, para a demarcação de fronteiras políticas, por exemplo, a toponímia é ciência fundamental, ao mesmo tempo em que pode se remeter a fatores sociais, históricos, geográficos e até mesmo arqueológicos, no campo extralinguístico. As fronteiras internacionais brasileiras foram demarcadas ao longo do século XIX, na época do Império graças aos esforços do Visconde e do Barão do Rio Branco.

Segundo o linguista francês Dubois: "L'onomastique est une branche de la lexicologie étudiant l'origine des noms propres. On divise parfois cette étude en anthroponymie (concernant les noms propres de personnes) et toponymie (concernant les noms de lieux). (DUBOIS, 2002, p.334)".

Quanto à toponímia:

"La toponymie est l'étude de l'origine des noms de lieux, de leurs rapports avec la langue du pays, les langues d 'autres pays ou des langues disparues. La matière est généralement divisée selon la géographie (il existe des spécialistes des noms de fleuves [hydronymie], des noms de montagnes [oronymie], des spécialistes aussi pour telle ou telle région déterminée). (DUBOIS, 2002, p.485)".

Topônimos, portanto, são substantivos que têm como referência espaços em que é registrada a atividade humana, por vezes apenas a ativida- 
de linguística, social e política de nomear e classificar. Morfologicamente os topônimos são substantivos próprios, sendo o seu estudo referente à Onomástica, campo de estudos que se subdivide, por vez, na Toponímia, que tem por objeto de estudos a origem dos topônimos e as mudanças que sofrem ao longo dos tempos, por vicissitudes históricas e sociais, como supracitado. Desta forma, a toponímia se relaciona com a Historiografia da Linguística, com a Geografia e até mesmo com a Arqueologia.

Os topônimos citados na Flora Brasiliensis sobre os caminhos percorridos por Carl F. P. von Martius, em 1818, compõem, em parte, as rotas da antiga Estrada Real, conhecidas como Caminho Velho, Caminho Novo, Caminho dos Diamantes e Sabarabuçu, sendo alguns dos topônimos citados ainda existentes (CARVALHO, 2012, p. 173 e 456). Há a descrição de rios, acidentes geográficos, nome de fazendas e plantações, que vão de São Paulo a Minas Gerais. Atualmente, o Instituto Estrada Real cuida da preservação da memória dos caminhos que se converteram em projeto de desenvolvimento turístico nestas regiões.

No Brasil, atualmente, o IBGE é representante nacional perante à ONU nos congressos internacionais quinquenais sobre nomes geográficos, os topônimos:

"O IBGE representa o Brasil em conferências quinquenais promovidas pela ONU, e participa de projetos relacionados a nomes geográficos em parceria com o Instituto Panamericano de Geografia e História (IPGH), havendo inserido o Brasil na Rede de Nomes Geográficos das Américas. O Instituto está procurando recuperar o valor sociocultural e histórico da toponímia brasileira, reativando o interesse pela preservação e o resgate de uma Cartografia atualizada, completa e certificada por meio do Projeto Nomes Geográficos do Brasil (...)" (GOVERNO DO ESTADO DO PARANÁ, 2008, p. 18).

Na Universidade de São Paulo, foi desenvolvido o projeto Atlas Toponímico do Brasil e, em alguns Estados, projetos semelhantes tratam da pesquisa linguística e histórica dos topônimos brasileiros, buscando relatar as origens, as variações de topônimos a fim de fornecer informações históricas acerca do processo de ocupação do território. Este trabalho de toponímia, por fim, se desenvolve em perspectiva interdisciplinar, com a análise cartográfica, linguística e histórica, contribuindo para um melhor conhecimento acerca da ocupação territorial de nosso país, estados e municípios.

O relato de topônimos da obra Flora Brasiliensis, que apresentamos, foi escrito por Iganz Urban para a edição de 1906, como supracitado, 
tendo sido traduzido do alemão para o Latim Científico, nesta edição, porém, recolhido em português, em 1818, por Martius e Spix, e publicados em alemão em 1823, no primeiro volume da obra Reise in Brasilien (Viagem ao Brasil). Logo, este relato passou por um longo percurso, intercultural e plurilinguístico, até sua publicação na edição das Vitae Itineraque Collectorum Botanicorum (Vidas e itinerários dos botânicos coletores).

Grande parte dos topônimos descritos na viagem da Missão Austro-Alemã de 1818 são referentes aos caminhos e entradas da Estrada Real, abertos em época colonial, entre São Paulo, Minas Gerais, Goiás, chegando os naturalistas neste ano até à Bahia. Os naturalistas de então atravessavam essas distâncias com tropas de animais de carga, sobretudo mulas. Após a expedição de Martius e Spix, diversos outros naturalistas realizaram semelhantes trajetos, assim, como o fez Langsdorff em sua expedição em 1824 . 


\section{NEO-LATIN TOPONYMS IN FLORA BRASILIENSIS: report of the Austro-German Mission in Brazil in 1818}

\section{ABSTRACT}

The present article consists of a study in the field of History of Linguistics in Brazil, that has as corpus of work the register of toponyms in scientific Neo-Latin in Flora Brasiliensis, a book which recorded the path of the Austro-German Mission in the year 1818 in Brazil, the expedition of the german naturalists Carl F. P. von Martius and Johann S. B. von Spix. In addition to the establishment of text and translation of the scientific Latin account, written by Ignaz Urban and published in 1906, the article presented the contextualization of the scientific works of these naturalists, the use of scientific Latin in the nineteenth century and the context of toponymic studies in the History of Linguistics, currently in Brazil. The route traveled in Brazil by Spix and Martius in 1818, recorded in the work, between the present states of São Paulo, Minas Gerais, Goiás and Bahia, is part of the old roads of the Estrada Real.

KEYWORDS: History of Linguistics. Scientific Latin. Carl F. P. von Martius. 


\section{REFERÊNCIAS}

BARBOSA, Susana. Hegel y Darwin: historia, evolución, y el lugar de América. Enfoques, v. XXV, n. 2, p. 93-109, primavera de 2013.

BARRETO, Célia de Barros et al. O Brasil monárquico, tomo II: o processo de emancipação. Rio de Janeiro: Bertrand Brasil, 2003.

CARVALHO, Francisco de Assis. Entre a palavra e o chão: memória toponímica da Estrada Real. 2012. 535f. Tese (Doutorado). Faculdade de Filosofia, Letras e Ciências Humanas. Departamento de Linguística. Universidade de São Paulo, São Paulo. 2012.

CRIA, Flora Brasiliensis. São Paulo, 2005. Disponível em: $<$ http://florabrasiliensis.cria.org.br/>. Acesso em: 20 dez. 2016.

DIENER, Pablo. Martius e as ínguas indígenas do Brasil. Revista Brasileira de Linguística Antropológica, v. 6, n. 2, p. 353-376, dez. 2014.

DUBOIS, Jean et al. Dictionnaire de linguistique. Paris: Larousse, 2002.

FARACO, Carlos Alberto. História sociopolítica da língua portuguesa. São Paulo: Parábola, 2016.

FORCELLINI, E. Totius latinitatis lexicon. Lipsiae: Sumptibus Ch. E. Hahniani, 1835 .

GOVERNO DO ESTADO DO PARANÁ Projeto nomes geográficos do Estado do Paraná "Toponímia passo a passo". Curitiba, 2008. Disponível em: <http:// www.itcg.pr.gov.br/arquivos/File/Produtos_DGEO/PNGPR/PNGPR DocumentoReferencial.pdf>. Acesso em: 21 dez. 2016.

GUIMARÃES, M. L. S. História e natureza em von Martius: esquadrinhando o Brasil para construir a nação. História, Ciências, Saúde - Manguinhos, vol. VII, n.2, 389-410, jul./out. 2000.

MARTIUS, Carl Friedrich Philipp von. Flora brasiliensis - volumen I, pars I. Monachii: 1840-1846.

. Como se deve escrever a história do Brasil. Revista Trimensal de

História e Geographia do IGHB, vol. 6, n 24, p.381-403, jan. 1845.

GENERAL CHARTE von Südamerika of Martius and Spix. Disponível em:

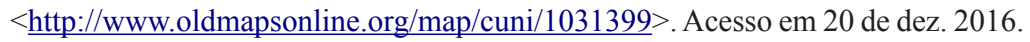

MORAES, L. R. de \& FALCADE, A. The lauraceous collections of Carl Friedrich Philipp von Martius in the Flora Brasiliensis. Harvard Papers in Botany, v. 20, n. 2, p. 167-197, dez. 2015.

RIZZINI, Carlos Toledo. Latim para botânicos. Ensaio sobre o uso do Latim 
na Botânica. Bahia: Fundação Gonçalo Muniz, 1955.

ROYAL SOCIETY. Obituary Notices of Fellows Deceased Source. Proceedings of the Royal Society of London, v. 18, p. 1-40, 1869 - 1870.

ROSENTHAL, Erwin Theodor. Apresentação. In: MARTIUS, Carl Friedrich Philipp von. Frei Apolônio: um romance do Brasil. Trad. Erwin Theodor Rosenthal. São Paulo: Brasiliense, 1992. Apres., p. 5-33.

SARAIVA, F. R. dos Santos. Novíssimo dicionário latino-português. Rio de Janeiro: Garnier, 2000.

SEVERO, C. G. A diversidade linguística como questão de governo. Calidoscópio, v. 11, n. 2, p. 107-115, mai/ago 2013.

SPIX \& MARTIUS. Viagem ao Brasil. Trad, Lúcia Furquim Lahmeyer. São Paulo: Edusp, 1981.

URBAN, I. 1906. Vitae itineraque collectorum botanicorum, Notae collaboratorum biographicae. In: MARTIUS, C.F.P von et al. Flora Brasiliensis ratio edendi chronologica, Systema, Index Familiarum. München e Leipzig: R. Oldenbourg, 1906, p. 1-268.

Recebido em: 22/12/2016

Aceito em: 11/06/2017 